\title{
Understanding CEAB's Graduate Attributes Criterion As A Department: The University Of Manitoba Biosystems' Experience
}

\author{
Danny D. Mann ${ }^{1}$ and Jason Morrison ${ }^{1}$ \\ ${ }^{1}$ Department of Biosystems Engineering, University of Manitoba, Winnipeg, MB \\ Corresponding Author E-mail Address: Jason_Morrison@umanitoba.ca
}

\begin{abstract}
With the approach of the accreditation visit by the Canadian Engineering Accreditation Board, it falls to the faculties and departments to interpret, understand and transition into use the latest accreditation criterion on graduate attributes. Over the past two years Biosystems has utilized our small size to perform several preparatory exercises to understand graduate attributes and how they relate to classes offered by our department. This has included several iterations of assessing the level of competency expected from students, an explanation of how attributes are developed by each course, development of learning outcomes, an integration of these ideas into course outlines and a preliminary investigation into how to report these items in a summative and informative manner. This work presents the process followed, observations on how it could be shortened and a brief discussion of the difficulties aligning course-based assessments to curriculum wide needs.
\end{abstract}

\section{Keywords:}

CEAB Attributes, Understanding Learning Outcomes

\section{INTRODUCTION}

The Department of Biosystems Engineering has been able to capitalize on our small size and unique position to facilitate a variety of organized preparatory tasks to evaluate our students and courses regarding the Canadian Engineering Accreditation Board's (CEAB's) graduate attributes. Some tasks have been initiated and completed within the Department, while others have been achieved together with representatives from other departments in the Faculty of Engineering. Overall, we have undertaken a multipronged approach of assessing professors targeted outcomes, students perceptions, and employers desires and perceptions. We have been fortunate that our Department has dual affiliations with both the Faculty of Engineering and the Faculty of Agricultural \& Food Sciences. Our teaching responsibilities to the Faculty of Agricultural \& Food Sciences meant that we were engaged in that faculty's independent curriculum review that targeted a learning outcomes assessment of all courses (that ended in the summer of 2010). Although the engineering courses taught by the Department of Biosystems Engineering were not part of the curriculum review in the Faculty of Agricultural \& Food Sciences, it was decided that teaching objectives and learning outcomes should be prepared for all BIOE courses for the 2010-2011 academic year. Thus, we first tackled the CEAB graduate attributes in 2010 in the context of just having prepared teaching objectives and learning outcomes for our courses. This was a fortunate coincidence.

\section{FACULTY ASSESSMENT OF COURSES}

Over the past two years, several steps have been taken to better understand what is being taught in our biosystems engineering (BIOE) courses. As mentioned above, the first analysis, which consisted of preparing teaching objectives and learning outcomes of our courses for inclusion in course outlines, was not done in the context of the CEAB graduate attributes. A key element in this endeavour was to use Bloom's taxonomy and relevant example verbs in describing the expected level of student achievement for each learning outcome [1, Appen. B]. Using a common learning taxonomy ensured a common reference for categorizing outcome levels.

The first attempt to map BIOE courses to CEAB graduate attributes occurred in December 2010 when course instructors were asked to complete a survey of how $\mathrm{CEAB}$ attributes are addressed by the teaching objectives, course content and expected learning outcomes for each of the department's courses. This process used a refined set of learning levels corresponding to: a) Knowledge/Comprehension; b) Application/ Analysis; and c) Synthesis/Evaluation. It was observed that each instructor seemed to think it was necessary for each course to address as many of the twelve graduate attributes as possible. Review of these survey results was important because it helped us to understand that we must choose only the CEAB graduate attributes that are most important in each of our BIOE courses (rather than trying to address each attribute in each course). 
Our next and most recent assessment of the courses was to revisit the objectives and outcomes and map them to the CEAB attributes. This time the goal was to list approximately 5 outcomes (that represent only the key outcomes for the course) and the expected level of competence for each key outcome (using Bloom's taxonomy). Instructors were asked to limit the number of attributes addressed by each learning outcome (ideally no more than two attributes per learning outcome). This was done to facilitate ultimate evaluation of the attributes. At this stage, a decision was made that all BIOE technical electives should address the same graduate attributes to simplify minimum path analysis of the program. Instructors of BIOE technical electives were asked to write learning outcomes following a model. Currently, learning outcomes which are mapped to CEAB graduate attributes are included on all BIOE course outlines.

\section{OBSERVATIONS}

This paper describes the process undertaken by the Department of Biosystems Engineering to develop an initial mapping of the CEAB graduate attributes to our courses. It was a distinct advantage to have first gone through the process of preparing teaching objectives and learning outcomes for each of the courses. Likewise, the intermediate step of getting instructors to provide examples from their courses for each of the graduate attributes provided much useful information. The current version of learning outcomes that are mapped to the graduate attributes using Bloom's taxonomy is a good basis from which to initiate further review of the curriculum.

A concern that has arisen, however, is that Bloom's taxonomy may not provide useful classifications for all of the graduate attributes. In some cases, it was difficult to assign a Bloom's level to stated learning outcomes because the terminology does not seem to make sense. This is an issue that we hope to address in the future. Research is being planned to investigate whether other learning taxonomies may be more appropriate for some of the graduate attributes.

It is also important to recognize that the process described in this paper was undertaken parallel to participation in a faculty-wide accreditation committee. This committee was a good resource to discuss ideas and to generate standardized procedures to be followed by all engineering departments. Standardization is essential when individual programs consist of courses taught by several engineering programs.

Although not the topic of this paper, it is important to remember that assessment of graduate attributes must ultimately be completed. The faculty-wide accreditation committee was instrumental in initiating discussion related to attribute assessment. A number of ideas were piloted by various departments. At times, however, there seemed to be a lack of clarity about how all of these topics fit together. From a Department perspective, the process seemed to gain clarity when it was realized that graduate attributes were being considered from three perspectives: 1) the perspective of the individual instructor who knows what is being taught at the individual course level, 2) the perspective of the program administrator who needs to oversee the entire program, and 3 ) the perspective of the student who must be able to demonstrate what has been learned. The topic of this paper essentially addresses the first perspective because we have simply mapped learning outcomes in individual courses to the graduate attributes using Bloom's taxonomy. It must be remembered that this is simply our perception (as instructors) of what is being taught in our courses. Some of our preliminary data show that students perceptions of what they have learned do not always closely match with instructors perceptions of what is being taught in the course, but that is a story for another day....

\section{References}

[1] Norman Edward Gronlund, How to write and use instructional objectives. Macmillan, 1995 ( $5^{\text {th }}$ ed.), $571 \mathrm{pp}$. \{ISBN: 978-0-023-48011-9\} 